\title{
The Graduated-Payment Mortgage: Solving the Initial Payment Enigma
}

By: Daniel T. Winkler G. Donald Jud

Winkler, D. T. and G. D. Jud. "The Graduated Payment Mortgage: Solving the Initial Payment Enigma, Journal of Real Estate Practice and Education, vol. 1, no. 1, 1998, pp. 67-79.

Made available courtesy of American Real Estate Society: http://cbeweb-1.fullerton.edu/finance/jrepe/

\section{***Note: Figures may be missing from this format of the document}

\begin{abstract}
:
Executive Summary: The graduated-payment mortgage (GPM) has a unique stair-step payment schedule that often enhances borrower qualification for young, first-time home buyers who are anticipated to have increasing incomes. The determination of the initial payment on a GPM mortgage is often regarded as complex; therefore, textbook authors normally disregard its theoretical development and substitute instead GPM interest factor tables. This study develops a general equation for finding the initial payment on a GPM and programmable calculator and computer spreadsheet routines for implementing the general equation. This approach enhances the technical understanding of the GPM, and it offers more flexibility than a table approach.
\end{abstract}

\section{Article:}

\section{INTRODUCTION}

The graduated-payment mortgage (GPM) was designed in the mid-1970s as an alternative to a fixed-rate mortgage; the primary motivation for its development was an effort by the Department of Housing and Urban Development to lower monthly mortgage loan payments during the first few years following a loan's inception. The stair-step payment schedule of a GPM often improves borrower qualification and it is particularly appealing to younger, first-time home buyers whose incomes are expected to rise (Sirota, 1992). The GPM payments increase yearly for a predetermined number of years; most GPMs have five or ten yearly payment increases. Thereafter, the payments are level, but the final stream of payments is higher than a fixed-rate loan with the same interest rate.

Lenders and textbook authors rely on GPM factor tables to determine the payment schedule (Wiedemer, 1995; Sirota, 1992). Even Brueggeman and Fisher (1997, p. 116) in their advanced real estate finance textbook note that "Computing initial payments on a mortgage of this kind is complex." Consequently, textbooks ignore the development of the initial payment on a GPM. From a pedagogical perspective, this omission is unfortunate because students and lenders should understand the time value of money underpinnings of the GPM.

Graduated payment schedules offered by HUD (Sec. 245 loans) are limited to only five plansthree five-year and two ten-year plans. Graduated-payment plans and corresponding tables to meet individual needs of borrowers are not available. For example, a borrower may desire a rate of increase in mortgage payments that does not correspond to the choices available in the five- or 
ten-year plans; the borrower may also seek a graduated-payment schedule for some period other than five or ten years. For lenders and borrowers, the table approach has substantial limitations.

The purpose of this article is to demonstrate the development of a generalized equation for finding the initial GPM payment, and routines for implementing the generalized equation using a programmable calculator or computer spreadsheet. For a pedagogical perspective, we develop the graduated-payment solution through a Time Value of Money (TVM) approach.

A typical GPM plan is shown in Exhibit 1, which illustrates the payments associated with a thirty-year, \$60,000 GPM with a fixed annual interest rate of $12 \%$ and payments increasing for five years. In this plan, the payments rise $7.5 \%$ annually for the first five years, that is, the growth rate $(g)$ in payments is $7.5 \%$, and the graduation period $(N)$ to full amortization is five years. The initial payment in this example is $23.06 \%$ below the thirty-year, full-amortization payment of $\$ 617.17$. The required payment rises each year at the rate of $7.5 \%$ to a level at the end of year 5 that is $10.45 \%$ above the thirty-year-level payment. At graduation following year 5, the full-amortization payment is \$681.67. The HUD Handbook for the Graduated Payment Mortgage Program (4240.2 rev) reports mortgage loan payments and the principal balance each year per $\$ 1,000$ loan amount for five GPM graduated-payment plans. For this example, the payment is shown as $\$ 7.9138$ per $\$ 1,000$ (App. 5, p. 3) for the first year, which results in the $\$ 474.83$ for a $\$ 60,000$ mortgage loan. Exhibit 2, a graph of payments and the principal balance on a $\$ 1,000$ mortgage loan, shows the occurrence of negative amortization in the early years. Negative amortization is an increase in principal balance that occurs because the mortgage loan payment is less than the interest portion of the payment; the shortfall is added to principal.

\begin{tabular}{|c|c|c|}
\hline \multicolumn{3}{|c|}{$\begin{array}{l}\text { Exhibit } 1 \\
\text { Graduated Payments }(g=7.5 \% \text { annually) for a Thirty-Year, } \\
12 \%, \$ 60,000 \text { Loan }\end{array}$} \\
\hline Year & $\begin{array}{c}\text { Graduated } \\
\text { Payment }\end{array}$ & $\begin{array}{l}\text { Ending } \\
\text { Balance }\end{array}$ \\
\hline 1 & $\$ 474.83$ & $\$ 61,587.47$ \\
\hline 2 & 510.44 & $62,924.59$ \\
\hline 3 & 548.72 & $63,945.91$ \\
\hline 4 & 589.87 & $64,574.84$ \\
\hline 5 & 634.11 & $64,722.46$ \\
\hline $6-30$ & 681.67 & $64,285.55$ \\
\hline Constant Payment & 617.17 & \\
\hline
\end{tabular}

Source: Brueggeman and Fisher (1997), p. 117. 


\section{Exhibit 2}

Payments and Loan Balance on a 7.5\%, Five-Year GPM

(Thirty-Year, \$1000 Loan @ 12\% APR)

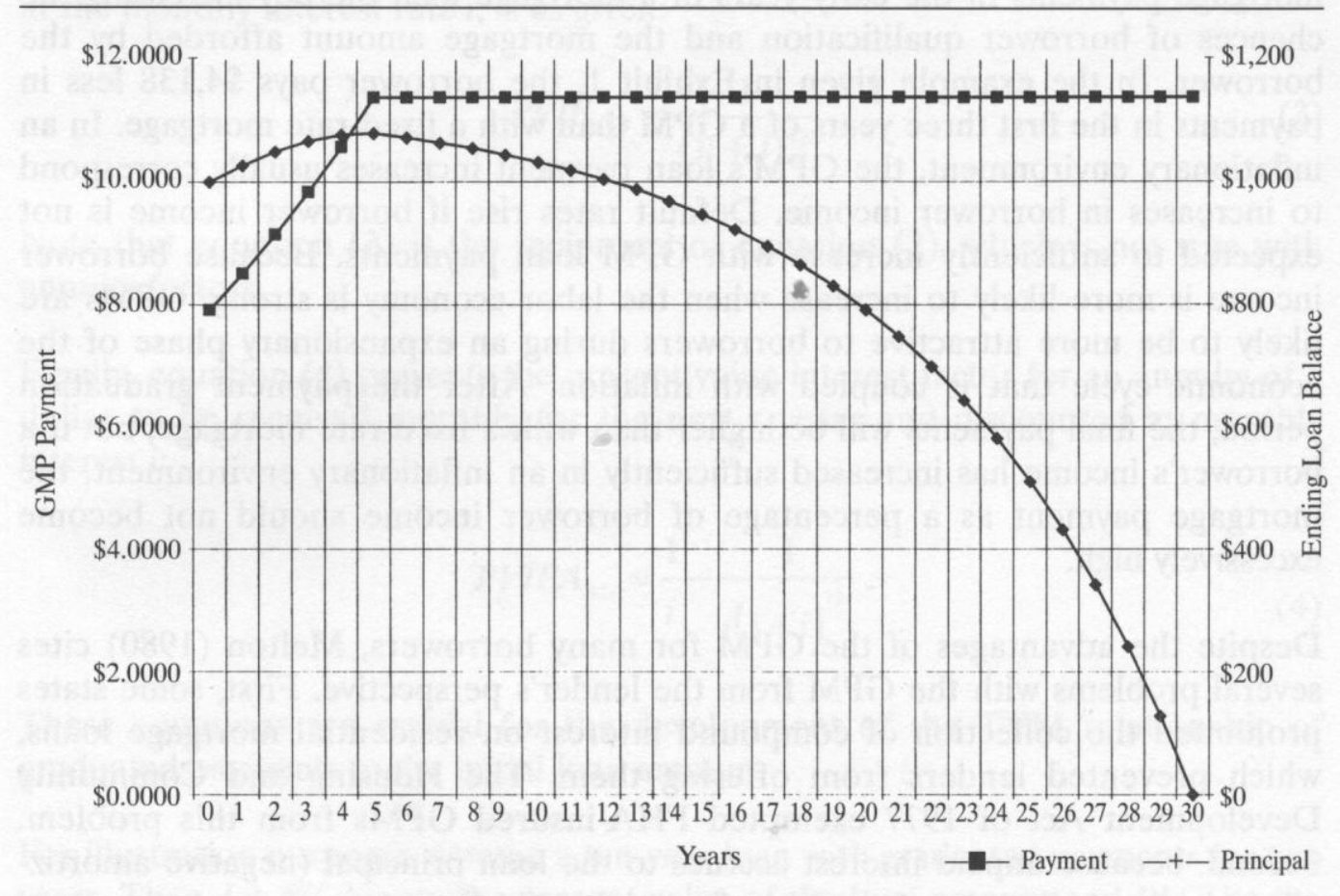

\section{BACKGROUND}

The GPM was an outgrowth of the "flexible payment" mortgage authorized by the Federal Home Loan Bank Board in February 1974, which omitted amortization in the early years of the mortgage (Melton, 1980). In the same year, Sec. 245 of the National Housing Act authorized HUD to initiate an experimental program to insure mortgage loans with varying amortization rates to correspond with variations in family income; the program became permanent in 1977. The GPM plans came into wide use in the late 1970s and early 1980s because, in an environment of high inflation and high interest rates, GPMs enabled young, first-time home buyers to purchase homes with lower initial payments (Wiedemer, 1995). By the end of 1978, over 25\% of single-family endorsements were GPMs (Melton, 1980).

The GPM program from HUD offered five alternatives; three plans offered $2^{1} / 2 \%, 5 \%$ and $7^{1} / 2 \%$ increases in payments annually for five years, and two plans offered $2 \%$ and $3 \%$ increases annually for ten years. For all five plans, payments were fixed for the twelve months between the annual payment increases; after the final graduated payment plateau was reached, the payments remained the same for the remaining term of the thirty-year mortgage loan.

The GPM has the advantage of reducing the burden of the tilt effect (Brueggeman and Fisher, 1997). That is, when inflationary expectations are high, the high expected inflation rates are incorporated in the interest rates, requiring borrowers to make much higher current real dollar payments from their current real income for the fixed-payment mortgage. The GPM significantly reduces the level of mortgage payments in the early years of a mortgage loan thereby increasing the chances of borrower qualification and the mortgage amount afforded by the borrower. In the 
example given in Exhibit 1, the borrower pays $\$ 4,138$ less in payments in the first three years of a GPM than with a fixed-rate mortgage. In an inflationary environment, the GPM's loan payment increases usually correspond to increases in borrower income. Default rates rise if borrower income is not expected to sufficiently increase with GPM loan payments. Because borrower income is more likely to increase when the labor economy is strong, GPMs are likely to be more attractive to borrowers during an expansionary phase of the economic cycle that is coupled with inflation. After the payment graduation period, the final payments will be higher than with a fixed-rate mortgage, but if a borrower's income has increased sufficiently in an inflationary environment, the mortgage payment as a percentage of borrower income should not become excessively high.

Despite the advantages of the GPM for many borrowers, Melton (1980) cites several problems with the GPM from the lender's perspective. First, some states prohibited the collection of compound interest on residential mortgage loans, which prevented lenders from offering them. The Housing and Community Development Act of 1977 exempted FHA-insured GPMs from this problem. Second, because unpaid interest accrues to the loan principal (negative amortization) in the early years of the loan, financial institutions reporting income on an accrual basis incur a tax liability. Third, from a default risk perspective, negative amortization occurs in the early years of a GPM, thereby reducing the borrower's equity in the home (see Exhibit 1). Unless lenders believe property values will rise, they usually require a higher downpayment to offset the effects of negative amortization.

\section{FINDING THE INITIAL PAYMENT ON THE GPM}

The equation for the initial GPM payment is a straightforward, albeit somewhat messy, application of fundamental time-value-of-money relationships. The model we engage is one relating the loan value (present value (P11) to the present value of the future mortgage loan payment stream. We define future mortgage loan payments in terms of the initial payment (PMT) for the first twelve monthly payments; in subsequent years the payments increase annually at an annual growth rate of $g$ during the graduated-payment periods. Equation (1) is the future value factor interest factor for a $\$ 1$ mortgage loan payment, which increases at growth rate $g$, compounding for $t$ years as shown:

$$
F V I F_{g, t}=(1+g)^{t} .
$$

The future value of a dollar compounded monthly for $t$ years at a monthly interest rate $\mathrm{i}$ is defined in equation (2) as follows:

$$
F V I F_{i, 12 t}=(1+i)^{12 t}
$$

The present value interest factor for a dollar to be received in t years, discounted at the monthly interest rate $i$, is as given: 


$$
P V I F_{i, 12 t}=\frac{1}{(1+i)^{12 t}} .
$$

Note that equation (3) is the reciprocal of equation (2), which is not true with annuity factors.

Finally, equation (4) presents the present value interest factor for an annuity of a dollar to be received monthly for the next $\mathrm{t}$ years and discounted at monthly interest $i$ :

$$
\text { PVIFA }_{i, 12 t}=\frac{1}{i}-\frac{1}{i(1+i)^{12 t}} .
$$

These equations are crucial for the development of the TVM relationship of graduated payments to the initial loan amount.

For illustration purposes, assume a ten-year loan with graduated payments for two years. Then, let $P V$ denote the present value of the loan amount and $P M T$ be the monthly beginning payment at the inception of the loan. Using notation from equations (1), (3) and (4), the $P V$ of the GPM is expressed as:

$$
\begin{aligned}
P V=P M T\left(P V I F A_{i, 12 \cdot 1}\right) & +P M T\left(F V I F_{g, 1}\right)\left(P V I F A_{i, 12 \cdot 1}\right)\left(P V I F_{i, 12 \cdot 1}\right) \\
& +P M T\left(F V I F_{g, 2}\right)\left(P V I F A_{i, 96}\right)\left(P V I F_{i, 12 \cdot 2}\right) .
\end{aligned}
$$

In equation (5), the first series of multiplicative terms on the right-hand side is the present value at $\mathrm{t}=0$ of the initial twelve-payment annuity of payments $(P M T)$ received in year 1 . The second series of multiplicative terms denotes the present value at $t=0$ of the subsequent monthly payments received in year 2 . Note that payments during the second year increase from the initial payment $P M T$ by $F V I F_{g, l}$, where $g$ is the annual growth rate and $\mathrm{t}=1$ (time period in years). The present value (at $\mathrm{t}=1$ ) of the twelve-monthly-payment annuity during the second year is captured by $P V I F A_{i, 12.1}$, however, it is the $\mathrm{PVIF}_{\mathrm{i}, 12.1}$ term that brings this annuity stream from $t=1$ to $\mathrm{t}=0$. The third term in equation (1) is the present value of the remaining ninety-six-payment annuity starting after period 24 (payments 25 through 120). Note that the payment increases from PMT by $\left(F V I F_{g, 2}\right)$, and remains at that level for years 3 through 30 . The $\left(P V I F A_{i, 96}\right)$ term is necessary to find the present value of the ninety-six remaining payments, and this is the value of the annuity at the end of two years $(\mathrm{t}=2)$. The value of the ninetysix-payment annuity at $t=2$ is brought to the present by the term $\left(P V I F_{i, 12.2}\right)$. Once this relationship is established, solving for the initial payment is just a matter of simplifying equation (5) and solving for PMT.

Rearranging equation (5), substituting equation (2) for equation (3) and solving for $P M T$ results in equation (6) as given: 


$$
P M T=\frac{P V}{\left[1+\frac{F V I F_{g, 1}}{F V I F_{i, 12}}\right] P V I F A_{i, 12}+\left(F V I F_{g, 2}\right)\left(P V I F A_{i, 96}\right)\left(P V I F_{i, 24}\right)}
$$

The denominator of equation (6) is the present value interest factor for a graduated annuity mortgage, or in short, the graduated annuity interest factor. This factor consists of the individual future-value, present-value, and annuity interest factors for different maturities according to the timing of scheduled payments.

Equation 7 substitutes algebraic expressions in equations (1) through (4) for the financial symbolic notation; using the algebraic expressions for $F V I F_{g, t}, P V I F_{i, t}$, and $P V I F A_{. i, t}$ shown in equations (1) through (4):

$$
P M T=\frac{P V}{\left[1+\frac{(1+g)^{1}}{(1+i)^{12}}\right]\left[\frac{1}{i}-\frac{1}{i(1+i)^{12}}\right]+\left[\frac{(1+g)^{2}}{(1+i)^{24}}\right]\left[\frac{1}{i}-\frac{1}{i(1+i)^{96}}\right]}
$$

This substitution permits the solution by use of a scientific calculator.

The generalized solution for the initial GPM payment is shown in equation (8) as the number of annual graduation payments $\mathrm{N}$, the years to maturity $\mathrm{M}$ of the mortgage loan, and annual payment growth rate $g$ :

$$
P M T=\frac{P V}{\left[1+\sum_{t=1}^{N-1} \frac{(1+g)^{t}}{(1+i)^{12 t}}\right]\left[\frac{1}{i}-\frac{1}{i(1+i)^{12}}\right]+\left[\frac{(1+g)^{N}}{(1+i)^{12^{N}}}\right]\left[\frac{1}{i}-\frac{1}{i(1+i)^{12 M-12 N}}\right]}
$$

To illustrate the use of equation (8), refer to the example given in Exhibit 1. In this example, $P V$ $=\$ 60,000, i=1 \%$ (12\% annually), and $g=7.5 \%$ annually for five years. The graduated annuity interest factor is shown in the denominator of equation (9) as 126.3423, rendering an initial payment is $\$ 474.83$ as shown in equation (9): 


$$
\begin{aligned}
P M T= & \frac{P V}{\left[1+\frac{(1.075)^{1}}{(1.01)^{12}}+\frac{(1.075)^{2}}{(1.01)^{24}}+\frac{(1.075)^{3}}{(1.01)^{36}}+\frac{(1.075)^{4}}{(1.01)^{48}}\right]} \\
& \frac{1}{\left[\frac{1}{.01}-\frac{1}{.01(1.01)^{12}}\right]+\frac{(1.075)^{5}}{(1.01)^{60}}\left[\frac{1}{.01}-\frac{1}{.01(1.01)^{300}}\right]} \\
& =\frac{\$ 60,000}{51.3115938442+75.0307156435} \\
& =\$ 474.83 .
\end{aligned}
$$

Once this initial payment is found, successive payments for years 2 through 6 are determined by finding the future value of this payment (i.e., $\mathrm{FV}=\$ 474.83(1+g)^{t}$, where $\mathrm{t}$ runs from 1 to $\mathrm{N}$, the year of graduation. In the example, t extends from 1 to 5 , and the payment levels in year 6 .

\section{APPLICATION OF THE GPM GENERALIZED EQUATION}

The generalized GPM equation given in equation (9) is best implemented using a programmable calculator such as the Hewlett Packard (HP) 17B (or HP19B) or a spreadsheet such as Lotus 1-23 or Microsoft Excel. For the HP 17B, the user needs to enter into the equation solver in the main menu (SOLVE) and create the following new equation (NEW) as one line (spaces are ignored by SOLVE):

$$
\begin{aligned}
G P M=P V \div & ((\Sigma(T: 1: N-1: 1: S P F V(G: T) \div \operatorname{SPFV}(I: 12 X T))+1) X \\
& U S P V((I: 12)+\operatorname{SPFV}(G: N) \div \operatorname{SPFV}(I: 12 X N) X \\
& U S P V(I:(12 X M)-(12 X N)))
\end{aligned}
$$

Once entered correctly, the user should press CALC in the SOLVE menu to verify the equation. The user then enters PV, N, G, i, and M. It should be noted that N and M are in years, G is annual interest rate, and $\mathrm{i}$ is a monthly interest rate. As an alternative to the one-step approach, the user can define the term in parentheses as the graduated annuity interest factor (GAIF) and then do a second equation that defines the GPM as PV/GAIF; the HP 17B and HP 19B automatically store the GAIF value from the first step. The advantage of the two-step approach is that the GAIF can be used separately, for example, to find the present value of a loan 
Exhibit 3

$$
\begin{array}{ll}
P V=\$ 60000.00 & g=0.07 \\
i \cdot=0.01 & M=30
\end{array}
$$

(1)

(2)

(3)

(4)

(5)

(6)

(7)

(8)

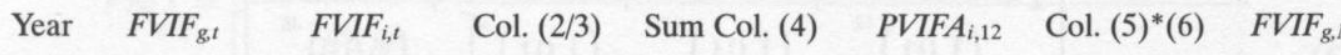

\begin{tabular}{lrllllll}
\hline 1 & 1.0000 & 1.0000 & 1.0000 & 1.0000 & 11.2551 & 11.2551 & 1.0750 \\
2 & 1.0750 & 1.1268 & 0.9540 & 1.9540 & 11.2551 & 21.9925 & 1.1556 \\
3 & 1.1556 & 1.2697 & 0.9101 & 2.8641 & 11.2551 & 32.2361 & 1.2423 \\
4 & 1.2423 & 1.4308 & 0.8683 & 3.7324 & 11.2551 & 42.0086 & 1.3355 \\
5 & 1.3355 & 1.6122 & 0.8283 & 4.5607 & 11.2551 & 51.3316 & 1.4356 \\
6 & 1.4356 & 1.8167 & 0.7902 & 5.3510 & 11.2551 & 60.2258 & 1.5433 \\
7 & 1.5433 & 2.0471 & 0.7539 & 6.1049 & 11.2551 & 68.7110 & 1.6590 \\
8 & 1.6590 & 2.3067 & 0.7192 & 6.8241 & 11.2551 & 76.8059 & 1.7835 \\
9 & 1.7835 & 2.5993 & 0.6861 & 7.5103 & 11.2551 & 84.5285 & 1.9172 \\
10 & 1.9172 & 2.9289 & 0.6546 & 8.1648 & 11.2551 & 91.8960 & 2.0610 \\
11 & 2.0610 & 3.3004 & 0.6245 & 8.7893 & 11.2551 & 98.9245 & 2.2156 \\
12 & 2.2156 & 3.7190 & 0.5958 & 9.3851 & 11.2551 & 105.6299 & 2.3818 \\
13 & 2.3818 & 4.1906 & 0.5684 & 9.9534 & 11.2551 & 112.0268 & 2.5604 \\
14 & 2.5604 & 4.7221 & 0.5422 & 10.4957 & 11.2551 & 118.1295 & 2.7524 \\
15 & 2.7524 & 5.3210 & 0.5173 & 11.0129 & 11.2551 & 123.9516 & 2.9589 \\
16 & 2.9589 & 5.9958 & 0.4935 & 11.5064 & 11.2551 & 129.5059 & 3.1808 \\
17 & 3.1808 & 6.7562 & 0.4708 & 11.9772 & 11.2551 & 134.8047 & 3.4194 \\
18 & 3.4194 & 7.6131 & 0.4491 & 12.4264 & 11.2551 & 139.8598 & 3.6758 \\
19 & 3.6758 & 8.5786 & 0.4285 & 12.8549 & 11.2551 & 144.6825 & 3.9515 \\
20 & 3.9515 & 9.6666 & 0.4088 & 13.2636 & 11.2551 & 149.2833 & 4.2479 \\
21 & 4.2479 & 10.8926 & 0.3900 & 13.6536 & 11.2551 & 153.6725 & 4.5664 \\
22 & 4.5664 & 12.2740 & 0.3720 & 14.0257 & 11.2551 & 157.8599 & 4.9089 \\
23 & 4.9089 & 13.8307 & 0.3549 & 14.3806 & 11.2551 & 161.8547 & 5.2771 \\
24 & 5.2771 & 15.5847 & 0.3386 & 14.7192 & 11.2551 & 165.6657 & 5.6729 \\
25 & 5.6729 & 17.5613 & 0.3230 & 15.0422 & 11.2551 & 169.3015 & 6.0983 \\
26 & 6.0983 & 19.7885 & 0.3082 & 15.3504 & 11.2551 & 172.7700 & 6.5557 \\
27 & 6.5557 & 22.2981 & 0.2940 & 15.6444 & 11.2551 & 176.0790 & 7.0474 \\
28 & 7.0474 & 25.1261 & 0.2805 & 15.9249 & 11.2551 & 179.2359 & 7.5759 \\
29 & 7.5759 & 28.3127 & 0.2676 & 16.1925 & 11.2551 & 182.2475 & 8.1441 \\
\hline & & & & & & &
\end{tabular}


Exhibit 3 (continued)

\begin{tabular}{|c|c|c|c|c|c|c|}
\hline (9) & (10) & (11) & (12) & (13) & (14) & (15) \\
\hline$F V I F_{i, 12 N}$ & Col. (8)/(9) & $P^{\prime} I F A_{i, 12 M-12 N}$ & Col. $(10)^{*}(11)$ & Col.(7)+(10) & $P M T / \$ 1000$ & $P M T$ \\
\hline 1.1268 & 0.9540 & 96.8655 & 92.4105 & 103.6656 & $\$ 9.65$ & $\$ 578.78$ \\
\hline 1.2697 & 0.9101 & 96.4680 & 87.7985 & 109.7911 & $\$ 9.11$ & $\$ 546.49$ \\
\hline 1.4308 & 0.8683 & 96.0201 & 83.3716 & 115.6077 & $\$ 8.65$ & $\$ 519.00$ \\
\hline 1.6122 & 0.8283 & 95.5153 & 79.1190 & 121.1276 & $\$ 8.26$ & $\$ 495.35$ \\
\hline 1.8167 & 0.7902 & 94.9466 & 75.0307 & 126.3623 & $\$ 7.91$ & $\$ 474.83$ \\
\hline 2.0471 & 0.7539 & 94.3056 & 71.0967 & 131.3225 & $\$ 7.61$ & $\$ 456.89$ \\
\hline 2.3067 & 0.7192 & 93.5835 & 67.3074 & 136.0184 & $\$ 7.35$ & $\$ 441.12$ \\
\hline 2.5993 & 0.6861 & 92.7697 & 63.6534 & 140.4594 & $\$ 7.12$ & $\$ 427.17$ \\
\hline 2.9289 & 0.6546 & 91.8527 & 60.1256 & 144.6542 & $\$ 6.91$ & $\$ 414.78$ \\
\hline 3.3004 & 0.6245 & 90.8194 & 56.7151 & 148.6110 & $\$ 6.73$ & $\$ 403.74$ \\
\hline 3.7190 & 0.5958 & 89.6551 & 53.4130 & 152.3375 & $\$ 6.56$ & $\$ 393.86$ \\
\hline 4.1906 & 0.5684 & 88.3431 & 50.2107 & 155.8406 & $\$ 6.42$ & $\$ 385.01$ \\
\hline 4.7221 & 0.5422 & 86.8647 & 47.0998 & 159.1266 & $\$ 6.28$ & $\$ 377.06$ \\
\hline 5.3210 & 0.5173 & 85.1988 & 44.0719 & 162.2014 & $\$ 6.17$ & $\$ 369.91$ \\
\hline 5.9958 & 0.4935 & 83.3217 & 41.1185 & 165.0701 & $\$ 6.06$ & $\$ 363.48$ \\
\hline 6.7562 & 0.4708 & 81.2064 & 38.2316 & 167.7375 & $\$ 5.96$ & $\$ 357.70$ \\
\hline 7.6131 & 0.4491 & 78.8229 & 35.4027 & 170.2074 & $\$ 5.88$ & $\$ 352.51$ \\
\hline 8.5786 & 0.4285 & 76.1372 & 32.6236 & 172.4835 & $\$ 5.80$ & $\$ 347.86$ \\
\hline 9.6666 & 0.4088 & 73.1108 & 29.8861 & 174.5686 & $\$ 5.73$ & $\$ 343.70$ \\
\hline 10.8926 & 0.3900 & 69.7005 & 27.1816 & 176.4649 & $\$ 5.67$ & $\$ 340.01$ \\
\hline 12.2740 & 0.3720 & 65.8578 & 24.5018 & 178.1744 & $\$ 5.61$ & $\$ 336.75$ \\
\hline 13.8307 & 0.3549 & 61.5277 & 21.8381 & 179.6980 & $\$ 5.56$ & $\$ 333.89$ \\
\hline 15.5847 & 0.3386 & 56.6485 & 19.1815 & 181.0362 & $\$ 5.52$ & $\$ 331.43$ \\
\hline 17.5613 & 0.3230 & 51.1504 & 16.5233 & 182.1890 & $\$ 5.49$ & $\$ 329.33$ \\
\hline 19.7885 & 0.3082 & 44.9550 & 13.8541 & 183.1556 & $\$ 5.46$ & $\$ 327.59$ \\
\hline 22.2981 & 0.2940 & 37.9740 & 11.1645 & 183.9345 & $\$ 5.44$ & $\$ 326.20$ \\
\hline 25.1261 & 0.2805 & 30.1075 & 8.4446 & 184.5236 & $\$ 5.42$ & $\$ 325.16$ \\
\hline 28.3127 & 0.2676 & 21.2434 & 5.6843 & 184.9202 & $\$ 5.41$ & $\$ 324.46$ \\
\hline 31.9035 & 0.2553 & 11.2551 & 2.8731 & 185.1207 & $\$ 5.40$ & $\$ 324.11$ \\
\hline
\end{tabular}

amount given the initial payment, number of graduated payments, loan maturity, and interest rate. 
Equation (9) can also be implemented using a computer spreadsheet such as Microsoft Excel.

Exhibit 3 provides an example of a spreadsheet for the $\$ 60,000$, thirty-year, 12\% APR loan with annual graduated payments that are permitted to vary from one to twenty-nine years. The GAIF factor for a thirty-year, $12 \%$ APR loan, with five-year graduated payments at $7.5 \%$ annually is 126.3623 , with a payment per $\$ 1,000$ of $\$ 7.9138$, and a payment on a $\$ 60,000$ loan equal to $\$ 474.83$. Looking at column (15), if payments are permitted to be graduated at $7.5 \%$ for one year, the payment would be $\$ 578.78$ in the first year and $7.5 \%$ higher at $\$ 622.19$ for the remaining twenty-nine years. If payments are graduated at $7.5 \%$ for ten years, the payment would be only $\$ 403.74$ in the first year but would plateau at $\$ 832.12$ in years $11-30$.

Exhibit 3 can be used to graph the graduated payments at $21 / 2 \%, 5 \%$ and $7.5 \%$ for five years and $2 \%$ and $3 \%$ for ten years (the current Sec. 245 HUD plans) to examine the sensitivity of payment increases to number of years that payments are graduated. Exhibit 4 indicates that the 5\% and 7.5\% graduated-payment plans have the largest impact on payments in the first year. The slope of graph for these two plans, however, suggests that graduating payments beyond ten years provides

\section{Exhibit 4}

Payment per \$1,000 Principal Thirty-Year, 12\% APR Mortgage

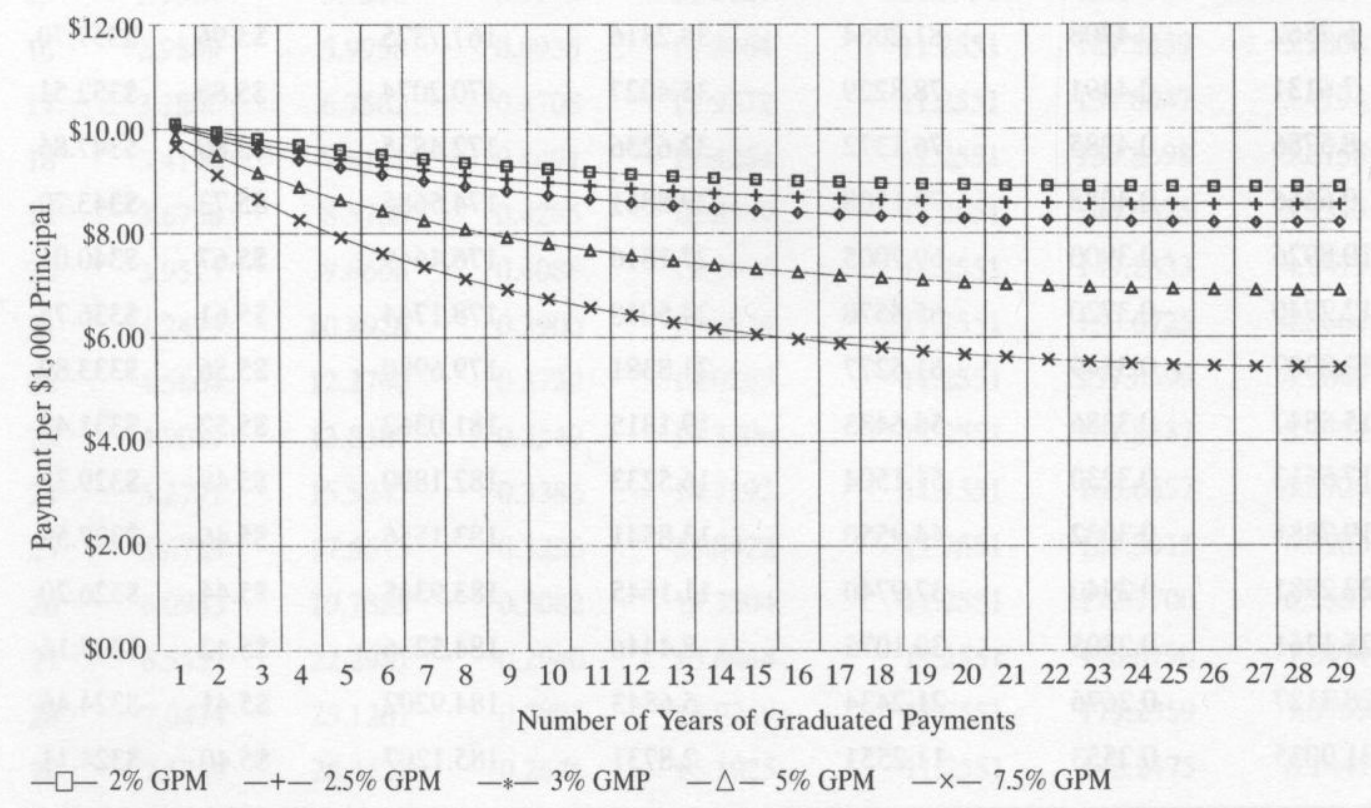

relatively little reduction in the initial payment. The $2 \%$ and $3 \%$ ten-year graduated-payment plans reduce the initial payment very little compared to the more aggressive five-year plans, a fact largely explained by the greater discounting of more distant payments. The more moderate increases in payments over the ten-year period, however, does tend to have an advantage in controlling default risk compared with the more aggressive five-year plans. 


\section{CONCLUSION}

This study illustrates the pedagogical development of a generalized equation for the calculation of the initial payment on a GPM. The generalized equation provides a helpful tool that can be used to calculate the payments on GPMs having various growth rates, graduation periods and maturities. The steps for implementing the generalized equation using a programmable calculator or computer spreadsheet are also shown to facilitate implementation of the generalized equation.

An analysis of the sensitivity of the five GPM plans offered by HUD indicates that the $5 \%$ and 7 $1 / 2 \%$ graduated-payment plans for five years are by far the most effective in reducing the initial payments. Also, graduated-payment plans that exceed ten years have relatively little impact on initial payments.

\section{Endnote}

The pledged-account GPM, where a portion of loan proceeds are placed in a savings account and are withdrawn gradually to supplement the lower GPM payment to become a constant payment, has become an effective method to circumvent the tax liability problem.

\section{References}

Brueggeman, W.B. and J.D. Fisher, 1997, Real Estate Finance and Investments, Chicago, Ill.: Irwin, tenth edition.

Goebel, P.R. and N.G. Miller, 1981, Handbook of Mortgage Mathematics and Financial Tables, Englewood Cliffs, N.J.: Prentice-Hall.

HUD Handbook, Graduated Payment Mortgage Program, Sec. 245, Washington, D.C.: GPO, June 1978, 4240.2 rev.

Lederman, J. and M.A. Celic, editors, 1991, Adjustable-Rate Mortgages and Mortgage-Backed Securities: The Complete Reference Guide, Homewood, Ill.: Business One Irwin.

Melton, WC., 1980, Graduated Payment Mortgages, FRBNY Quarterly Review, 5:1, 21-28.

Sirota, D., 1992, Essentials of Real Estate Finance, Chicago, Ill.: Dearborn Financial Publishing, sixth edition. Wiedemer, J.P, 1995, Real Estate Finance, Englewood Cliffs, N.J.: Prentice-Hall, seventh edition. 


\begin{tabular}{|c|c|c|c|c|c|c|c|c|}
\hline \multicolumn{9}{|c|}{ Appendix } \\
\hline & $\mathrm{A}$ & $\bar{B}$ & $\mathrm{C}$ & $\mathrm{D}$ & $E$ & $\bar{F}$ & $\mathrm{G}$ & $\mathrm{H}$ \\
\hline 1 & & & & & & & & \\
\hline 2 & & & & & & & & \\
\hline 3 & $P V=$ & 6.000 & & $g=$ & 0.075 & & & \\
\hline 4 & $i=$ & 0.01 & & $M=$ & 30 & & & \\
\hline 5 & & & & & & & & \\
\hline 6 & (1) & $(2)$ & (3) & (4) & (5) & (6) & $(7)$ & $(8)$ \\
\hline 7 & Year & $F V I F g, t$ & FVIFi, $t$ & Col. (2/3) & Sum (4) & PVIFA $_{i, 12}$ & CoL. $(5)^{*}(6)$ & $\mathrm{FVIFg,N}$ \\
\hline 8 & 0 & & & & & & & \\
\hline 9 & 1 & $-(1+\operatorname{SES} 3)^{\prime} A 8$ & $-(1+\mathrm{SBSA})^{\circ}\left(122^{*} \mathrm{~A} 8\right)$ & $-\mathrm{B} / \mathrm{C} 9$ & -D9 & -PV(SBSA,12,-1) & -Eg॰F9 & $=(1+$ SES3): $(A 8+1)$ \\
\hline 10 & $-A 9+1$ & $-(1+\operatorname{SES} 3)^{\circ} \cdot A 9$ & $-(1+S B S A)^{*}(12 * A 9)$ & $-\mathrm{B} 10 / \mathrm{C} 10$ & $-E 9+D 10$ & $-P V($ SBSA, 12,-1) & $=E 10 * \mathrm{~F} 10$ & $\left.-(1+\text { SESB) })^{(}(A)+1\right)$ \\
\hline 11 & $-\mathrm{A} 10+1$ & $-(1+$ SES3) $A 10$ & $-(1+$ SBSA) $(12 * A 10)$ & $-\mathrm{B} 11 \mathrm{C} 11$ & $-E 10+D 11$ & -PV(SBSA,12,-1) & $-E 11^{\circ} \mathrm{F} 11$ & 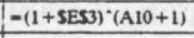 \\
\hline 12 & $-A 11+1$ & $-(1+\text { SES3 })^{*} A 11$ & $-(1+\text { SBSA })^{*}\left(12^{* A} \mathrm{~A} 11\right)$ & $-\mathrm{B} 12 / \mathrm{C} 12$ & $-E 11+D 12$ & -PV(SBSA,12,1) & $-\mathrm{E} 12^{*} \mathrm{~F} 12$ & $-(1+$ SES3) $(A 11+1)$ \\
\hline 13 & $-\mathrm{A} 12+1$ & $-(1+\text { SES3 })^{\circ} \cdot \mathrm{A} 12$ & $-(1+S B S A)^{*}(12 * A 12)$ & $-\mathrm{B} 13 \mathrm{C} \mathrm{Cl}_{3}$ & $-E 12+D 13$ & $-P \mathrm{PV}($ SBSA, 12,-1) & $-\mathrm{E} 13^{\circ} \mathrm{F} 13$ & $-(1+\operatorname{SES} 3)^{\circ}(A 12+1)$ \\
\hline 14 & $-A 13+1$ & $-(1+\text { SES3) })^{\circ} 13$ & $-(1+\operatorname{SBSA})^{\circ}\left(12^{*} \mathrm{~A} 13\right)$ & $-\mathrm{B} 14 \mathrm{C} / 4$ & $-E 13+D 14$ & -PV(SBSA,12,-1) & $-E\left[4^{*} \mathrm{~F} 14\right.$ & $-(1+\operatorname{SES} 3)^{\circ}(\mathrm{A} 13+1)$ \\
\hline 15 & $-A 14+1$ & $-(1+\text { SESO })^{\circ} A 14$ & $-(1+\operatorname{SBSA})^{*}\left(12^{*} \mathrm{~A} 14\right)$ & $-\mathrm{B} 15 \mathrm{~S}$ C15 & -E14+D15 & -PV'(SBSA.12.1) & -E15•F15 & $-(1+$ SES3) $(A 14+1)$ \\
\hline 16 & $-\mathrm{A} 15+1$ & $=(1+\text { SES3 })^{\circ} \mathrm{A} 15$ & $-(1+\text { SBSA) })^{*}(12 * A 15)$ & $-\mathrm{B} 16 / \mathrm{C} 16$ & $-E 15+D 16$ & - PV'(SBSA, 12, -1) & $-\mathrm{E} 16^{\circ} \mathrm{F} 16$ & $-(1+$ SESB) $($ A $15+1)$ \\
\hline 17 & $-A 16+1$ & $-(1+$ SES3) $A 16$ & $-(1+S B S A)^{*}(12 * A 16)$ & $-\mathrm{B} 17 / \mathrm{C} 17$ & $-E 16+D 17$ & -PV(SBSA,12, 1) & $-\mathrm{E} 17 * \mathrm{~F} 17$ & $-\left(1+\right.$ SESS3) $^{*}(\mathrm{~A} 16+1)$ \\
\hline 18 & $-A 17+1$ & $-(1+\text { SES3 })^{\circ} \cdot A 17$ & $-(1+\operatorname{SBSA})^{*}(12 * A 17)$ & $=\mathrm{B} 18 / \mathrm{C} 18$ & $-E 17+D 18$ & $=\mathrm{PV}($ SBSA $, 12,-1)$ & $-E 18^{\circ} \mathrm{F} 18$ & $-\left(1+\text { SESB }^{\prime}\right)^{\circ}(\mathrm{A} 17+1)$ \\
\hline 19 & $-A 18+1$ & $-(1+\text { SES3 })^{\circ} A 18$ & $-(1+\text { SBSA) })^{*}(12 * A 18)$ & $-\mathrm{B} 19 / \mathrm{C} 19$ & $-E 18+D 19$ & $=\mathrm{PV}$ (SBSA, 12.1) & -E19*F19 & $-(1+$ SES3) $(A 18+1)$ \\
\hline 20 & $-A 19+1$ & $-(1+\text { SES3 })^{\circ} \mathrm{A} 19$ & $-\left(1+\right.$ SBSA) $\left(12^{\bullet} A 19\right)$ & $-\mathrm{B} 20 . \mathrm{C} 20$ & $-E 19+D 20$ & $-P V^{\prime}($ SBSA $12,-1)$ & $-E 20^{*}+220$ & $-(1+\text { SES3) })^{\circ}(A 19+1)$ \\
\hline 21 & $-A 20+1$ & $-(1+\text { SES3) })^{\circ} 20$ & $-(1+$ SBSA) $(12 * A 20)$ & $-\mathrm{B} 21 / \mathrm{C} 21$ & $-\mathrm{E} 20+\mathrm{D} 21$ & $=P \mathrm{PV}($ SBSA, 12, 1) & $-\mathrm{E}_{2} 1 \cdot \mathrm{F}_{21}$ & $-\left(1+\right.$ SESS3 $^{\prime}(\mathrm{A} 20+1)$ \\
\hline 22 & $-A 21+1$ & $-(1+\operatorname{SESS3})^{\circ} \cdot \mathrm{A}^{21}$ & $-(1+S B S A)^{*}\left(12^{*} A 21\right)$ & $-\mathrm{BZ}_{\mathrm{C}} \mathrm{C2} 2$ & $-\mathrm{E} 21+\mathrm{D} 22$ & -PI'(BBSA, 12, 1) & $-E 22 \cdot \mathrm{F} 22$ & $-(1+\operatorname{SESS3})^{\circ}(A 21+1)$ \\
\hline 23 & $-A^{222+1}$ & $-(1+\operatorname{SESS3}) \cdot A 22$ & $-(1+\text { SBSA) })^{*}(12 * A 22)$ & $-\mathrm{B} 23 / \mathrm{C} 23$ & $-\mathrm{E}_{22} 2+\mathrm{D} 23$ & $=P V^{\prime}($ SBSA,12.-1) & $-\mathrm{E}_{2} 3 * \mathrm{P} 23$ & $-(1+$ SES3) $(A 22+1)$ \\
\hline 24 & $-\mathrm{A}_{23+1}$ & $-(1+\text { SES3 })^{\circ} A 23$ & $-(1+\text { SBSA) })^{*}\left(122^{\circ} \mathrm{A} 23\right)$ & $-\mathrm{B} 24 / \mathrm{C} 24$ & $-\mathrm{E} 23+\mathrm{D} 24$ & $-\mathrm{PV}^{\prime}($ SBSA, 12, 1) & $-\mathrm{E} 24 \cdot \mathrm{P} 24$ & $-(1+\operatorname{SESB})^{\circ}(A 23+1)$ \\
\hline 25 & $-\mathrm{A}_{24+1}$ & $-(1+$ SES3) $A 24$ & $-(1+\text { SBSA) })^{*}\left(12^{*} \mathrm{~A} 24\right)$ & $-825 / C 25$ & $-E 24+D 25$ & -PV'(SBSA, 12,-1) & -E2s*F2s & $-(1+\operatorname{SES} 3)^{\circ}(A 24+1)$ \\
\hline 26 & $-\mathrm{A}_{25+1}$ & $-(1+$ SES3 $) \cdot A 2 S$ & $-(1+\mathrm{SBSA})^{*}(12 * A 25)$ & $-826 \mathrm{C}_{26}$ & $=E 25+D 26$ & -PV(SBSA,12.-1) & $-E 26 \circ \mathrm{F} 26$ & $-(1+$ SES3) $($ A2S +1$)$ \\
\hline 27 & $-\mathrm{A} 26+1$ & $-(1+\text { SES3 })^{\circ} \mathrm{A} 26$ & $-(1+\$ B S A)^{*}(12 * A 26)$ & $-\mathrm{B} 27 / \mathrm{C} 27$ & $=\mathrm{E} 26+\mathrm{D} 27$ & -PI'(SBSA,12, 1) & $-E 27 \cdot F 27$ & $=(1+\operatorname{sESS3})^{\circ}(\mathrm{A} 26+1)$ \\
\hline 28 & $-A 27+1$ & $-(1+\text { SES3 })^{\circ} \cdot{ }^{-} 27$ & $-(1+\text { SBSA) })^{(12 * A 27)}$ & $-\mathrm{B} 28 / \mathrm{C} 28$ & $-E 27+D 28$ & -PV(SBSA,12,-1) & $-\mathrm{E} 28^{\circ} \mathrm{F} 28$ & $-(1+\operatorname{SESS3})^{\circ}(A 27+1)$ \\
\hline 29 & $-A .28+1$ & $=(1+\text { SES3 })^{\circ} A 28$ & $-(1+S B S A)^{*}\left(122^{*} A 28\right)$ & $-B 29: C 29$ & $-E 28+D 29$ & -PV(SBSA,12,-1) & - E290629 & $-(1+\operatorname{SESB})^{-}(A 28+1)$ \\
\hline 30 & $-\mathrm{A} 29+1$ & $-(1+\text { SES3) })^{\circ} 29$ & $-(1+$ SBSA) $(12 * A 29)$ & $-\mathrm{B} 30 / \mathrm{C} 30$ & $-E 29+D 30$ & -PV'(SBSA, 12, -1) & $-\mathrm{E} 30^{*} \mathrm{~F} 30$ & $-(1+$ SESB) $(A 29+1)$ \\
\hline 31 & $-A 30+1$ & $=(1+$ SES3 $) \cdot A 30$ & $=\left(1+\right.$ SBSA) $\left(12^{\circ} \mathrm{A} 30\right)$ & $-\mathrm{B} 31 / \mathrm{C} 31$ & $-E 30+D 31$ & -PV(SBSA,12,-1) & $-E 31 * \mathrm{~F} 31$ & $-(1+$ SESB) $(A 30+1)$ \\
\hline 32 & $-A 31+1$ & $-(1+\text { SES3) })^{\circ} 31$ & $-(1+S B S A)^{*}(12 * A 31)$ & $-\mathrm{B} 32 / \mathrm{C} 32$ & $-\mathrm{E} 31+\mathrm{D} 32$ & -PV(SBSA,12,-1) & $-\mathrm{E} 32^{\circ} \mathrm{F} 32$ & $-(1+$ SES3) $(A 31+1)$ \\
\hline 33 & $-A 32+1$ & $-(1+\text { SES3 })^{\circ}$ A32 & $-(1+\text { SBSA })^{*}\left(12^{*} A 32\right)$ & $-\mathrm{B} 33 / \mathrm{C} 33$ & $-E 32+D 33$ & -PV'(BBSA, 12,-1) & $-\mathrm{E} 33^{\circ} \mathrm{F} 33$ & $-(1+$ SES3) $(A 32+1)$ \\
\hline 34 & $-A .33+1$ & $-(1+\text { SES3 })^{\circ} A 33$ & $-(1+S B S A)^{*}(12 * A 33)$ & $-\mathrm{B34} / \mathrm{C} 34$ & $-\mathrm{E} 33+\mathrm{D} 34$ & -PV(SBSA,12,-1) & $-E 34^{\circ} \mathrm{F} 34$ & $-(1+\operatorname{SESS3})^{\circ}(A 33+1)$ \\
\hline 35 & $-A 34+1$ & $-(1+$ SES3) $A 34$ & $-\left(1+\right.$ SBSA) $\left(12^{*} A 34\right)$ & -B35/C35 & $-E 34+D 35$ & -PV'(SBSA,12,-1) & -E35॰F35 & $-(1+$ SES3) $(A 34+1)$ \\
\hline 36 & $-\mathrm{A} 35+1$ & $-(1+\operatorname{SES} 3)^{\circ} \mathrm{A} 3 \mathrm{~S}$ & $-(1+S B S A)^{*}\left(122^{*} A 3 S\right)$ & $-B 36 / C 36$ & $-E 35+D 36$ & -PI'(BBSA,12,-1) & $-E 36^{\circ} \mathrm{F} 36$ & $-(1+$ SES3) $(A 35+1)$ \\
\hline 37 & $-A 36+1$ & $-(1+$ SES3) $: A 36$ & $=(1+\operatorname{SBSA})^{\prime}\left(12^{*} \mathrm{~A} 36\right)$ & -Bת7:C37 & $-E 36+D 37$ & -PV(SBSA,12,-1) & $-E 37 \bullet \mathrm{P} 37$ & $-(1+$ SES3) $(A 36+1)$ \\
\hline
\end{tabular}


Appendix (continued)

\begin{tabular}{|c|c|c|c|c|c|c|}
\hline I & $\mathrm{J}$ & $\overline{\mathrm{K}}$ & $\mathrm{L}$ & $\bar{M}$ & $\mathrm{~N}$ & $\mathrm{O}$ \\
\hline & & & & & & \\
\hline & & & & & & \\
\hline & & & & & & \\
\hline & & & & & (14) & \\
\hline (9) & (10) & (11) & (12) & (13) & PMT per & $(15)$ \\
\hline$F V I F_{i, 12 N}$ & Col. $(8) /(9)$ & $P V I F A_{i, 12 M-12 N}$ & \begin{tabular}{|l|} 
Col. $(10)^{*}(13)$ \\
\end{tabular} & Col. (7)+(10) & $\$ 1,000$ & PMT \\
\hline$=(1+S B S A)^{*}(12 \%(A 8+1))$ & $-\mathrm{H} 9 / 19$ & -PV(SBSA.((SESA'12)-12*(A8+1)),-1) & $-199^{\circ} \mathrm{K} \theta$ & $-G 9+L 9$ & $-1 / \mathrm{M} 99 \cdot 1000$ & $-5853 / 1000 * N 9$ \\
\hline$-(1+S B S A)^{*}(129(A 9+1))$ & $-\mathrm{H} 10 / \mathrm{H10}$ & -PV(SBSA,((SESA•12)-124(A9+1)),-1) & $-\mathrm{J} 10^{\circ} \mathrm{K} 10$ & $-G 10+\mathrm{L} 10$ & $-1 / \mathrm{M} 10 * 1000$ & $-5853 / 1000^{\circ} \mathrm{N} 10$ \\
\hline$=(1+\operatorname{SBSA})^{*}(12 *(A 10+1))$ & $-\mathrm{H} 11 / \mathrm{L11}$ & -PV(SBSA,((SESA*12)-12*(A10+1)),-1) & $-\mathrm{J} 11 \cdot \mathrm{K} 11$ & $-\mathrm{G} 11+\mathrm{L} 11$ & $-1 / M 110^{*} 1000$ & - SBS3/1000॰N11 \\
\hline$-(1+\text { SBSA })^{*}(12 *(A 11+1))$ & $-\mathrm{H} 12 / \mathrm{L1} 2$ & -PV(SBSA.((SESA*12)-12*(A11+1)),-1) & $-\mathrm{J} 12 \cdot \mathrm{K} 12$ & $=G 12+L 12$ & $-1 / \mathrm{M} 12+1000$ & $-5 \mathrm{BS3} / 1000^{\circ} \mathrm{N} 12$ \\
\hline$-(1+5 B S A)^{*}(12 *(A 12+1))$ & $-\mathrm{H} 13 / \mathrm{I1} 3$ & -PV(SBSA,((SESA・12)-12*(A12+1)),-1) & $-\mathrm{J} 13^{\circ} \mathrm{K} 13$ & $-G 13+L 13$ & $-1 / \mathrm{M} 13 \cdot 1000$ & $-\$ B S 3 / 1000^{\circ} \mathrm{N} 13$ \\
\hline$-(1+5 B S A)^{*}(12 *(A 13+1))$ & $-\mathrm{H} 14 / 114$ & -PV(SBSA,((SES4*12)-124A13+1)),-1) & $-J 14^{\circ} \mathrm{K} 14$ & $-G 14+\mathrm{L} 14$ & $-1 / \mathrm{M} 14 \cdot 1000$ & $-\$ B 53 / 1000^{\circ} \mathrm{N} 14$ \\
\hline$=(1+\$ B S A)^{*}(124(A 14+1))$ & $=\mathrm{H} 15 / 115$ & -PV(SBSA.((SESA*12)-12ฯ(A14+1)),-1) & $-J 15 \bullet K 15$ & $-G 15+L 15$ & $-1 / \mathrm{M} 15 * 1000$ & - SBS3/1000nen:15 \\
\hline$=(1+S B S A) *(12 *(A 15+1))$ & $-\mathrm{H} 16 / 116$ & $=$ PV(SBSA, $(($ SESA*12)-12*(A1S+1)),-1) & $-516^{\circ} \mathrm{K} 16$ & $-G 16+\mathrm{L} 16$ & $=1 / \mathrm{M} 116^{\circ} 1000$ & $-5 \mathrm{BS3} 3 / 1000 \bullet \mathrm{N} 16$ \\
\hline$-(1+S B S 4)^{*}(12 *(A 16+1))$ & $-\mathrm{H} 17 / \mathrm{I11}$ & -PV(SBSA,((SESA*12)-124A16+1)),-1) & $-517^{\bullet} \mathrm{K} 17$ & $-G 17+L 17$ & $-1 / \mathrm{M} 117 * 1000$ & $-\mathrm{SBS3} / 1000^{*} \mathrm{~N} 17$ \\
\hline$-(1+S B S A)^{-}(12 *(A 17+1))$ & $-\mathrm{H} 18 / \mathrm{I18}$ & $=P V($ SBSA, $(($ SESA*12)-12*(A17+1)),-1) & $-J 18{ }^{\circ} \mathrm{K} 18$ & $-G 18+L 18$ & $-1 / \mathrm{M} 181^{\circ} 1000$ & $-5853 / 1000^{\circ} \mathrm{N} 18$ \\
\hline$-(1+\text { SBSA })^{*}(12 *(A 18+1))$ & - H19.119 & -PV(SBSA,((SESA*12)-12*A18+1)),-1) & $-\mathrm{J} 19{ }^{\circ} \mathrm{K} 19$ & $-G 19+\mathrm{L} 19$ & $-1 / \mathrm{M} 19{ }^{\circ} 1000$ & $-\$ B S 3 / 1000^{\circ} \mathrm{N} 19$ \\
\hline$-(1+5 B S 4)^{*}(12 *(A 19+1))$ & $-\mathrm{H} 20 / \mathrm{LO}$ & -PV(SBSA,((SESA+12)-12*(A19+1)),-1) & $-520 \cdot \mathrm{K} 20$ & $-\mathrm{G} 20+\mathrm{L} 20$ & $-1 / \mathrm{N} 20 * 1000$ & - SBS33/1000 $\mathrm{N} 20$ \\
\hline$=(1+5 B S A)^{*}(12 *(A 20+1))$ & $-\mathrm{H} 21 / \mathrm{D2}$ & $-P V($ SBSA, $(($ SESA*12)-12*(A20+1)),-1) & $-121 * \mathrm{~K} 21$ & $-\mathrm{G} 21+\mathrm{L} 21$ & $-1 / \mathrm{A} 21 \cdot 1000$ & -SBS3/10004N21 \\
\hline$=(1+\text { SBSA })^{-}(12 *(A 21+1))$ & $-\mathrm{H} 22 / \mathrm{D2}$ & $=P V($ SBSA, $(($ SESA*12)-12ฯ(A21+1)),-1) & $-122 \cdot \mathrm{K} 22$ & $-G 22+L 22$ & $-1 / M_{22} \cdot 1000$ & $-5 B 53 / 1000^{\circ} \mathrm{N} 22$ \\
\hline$=(1+S B S 4)^{*}(12 *(A 22+1))$ & $=\mathrm{H} 23 / \mathrm{Z} 23$ & $=P V^{\prime}($ SBSA, $(($ SESA*12)-12*(A22 +1)),-1) & $-123^{\circ} \mathrm{K} 23$ & $-G 23+L 23$ & $-1 / 2123 \cdot 1000$ & $-5 B 53 / 1000^{4} \mathrm{~N} 23$ \\
\hline$-(1+S B S 4)^{*}(12 *(A 23+1))$ & $-\mathrm{H} 24 / \mathrm{R} 4$ & $-P V$ (SBSA.((SESA*12)-12*(A23+1)),-1) & $-124^{\circ} \mathrm{K} 24$ & $-\mathrm{G} 24+\mathrm{L} 24$ & $-1 / \mathrm{A} 124 \cdot 1000$ & $-S B S 3 / 1000^{\circ} \mathrm{N} 24$ \\
\hline$=(1+5 B S 4)^{*}(12 *(A 24+1))$ & $-\mathrm{H} 25 / 25$ & -PV(SBSA,((SESA*12)-12*(A24+1)),-1) & $-125 * K_{2} 25$ & $-G 25+L 25$ & $-1 / \mathrm{A} 125 \cdot 1000$ & $-\$ B S 3 / 1000^{\circ} \mathrm{N} 25$ \\
\hline$=(1+5 B S 4)^{*}(12 *(A 25+1))$ & $-\mathrm{H} 26 / \mathrm{R} 6$ & -PV(SBSA,((SESA*12)-12*(A2S+1)),-1) & $-126{ }^{\circ} \mathrm{K} 26$ & $-G 26+L 26$ & $-1 / \mathrm{M} 26 \cdot 1000$ & $-5 B 53 / 1000^{\circ} \mathrm{N} 26$ \\
\hline$=(1+\operatorname{SBSA})^{*}(12 *(A 26+1))$ & $=\mathrm{H} 27 / 127$ & -PV(SBS4,((SES4*12)-12*(A26+1)),-1) & $-127^{\circ} \mathrm{K} 27$ & $-\mathrm{G} 27+\mathrm{L} 2 \mathrm{27}$ & $=1 / \mathrm{N} 127 \cdot 1000$ & $-\$ B \$ 3 / 1000^{*} \mathrm{~N} 27$ \\
\hline$-(1+\operatorname{SBSA})^{-}(12 \%(A 27+1))$ & $-\mathrm{H} 28 / 28$ & -PV(SBSA,((SESA*12)-12ฯ(A27+1)),-1) & $-\mathrm{J} 28 \cdot \mathrm{K} 28$ & $-G 28+L 28$ & $-1 / \mathrm{M} 28 \times 1000$ & $-5 B 53 / 1000 * N 28$ \\
\hline$=(1+\operatorname{SBSA})^{*}(124(\mathrm{~A} 28+1))$ & $-\mathrm{H} 29 / 129$ & -PV(SBSA,((SESA*12)-124(A28+1)),-1) & $-J 290 \mathrm{~K} 29$ & $-G 29+L 29$ & $-1 / \mathrm{M} 29 \cdot 1000$ & $-5853 / 1000 \% \mathrm{~N} 29$ \\
\hline$=(1+\operatorname{SBSA})^{\circ}(12 *(A 29+1))$ & $-\mathrm{H} 30 / 130$ & -PV(SBSA.((SESA•12)-124(A29+1)),-1) & $-\mathrm{J} 30 \cdot \mathrm{K} 30$ & $=G 30+L .30$ & $-1 / \mathrm{M} 30 \cdot 1000$ & $-\$ B S 3 / 1000 * N 30$ \\
\hline$-(1+S B S A)^{*}(12 \times(A 30+1))$ & $-\mathrm{H} 31 / \mathrm{L} 1$ & -PV(SBSA,((SESA*12)-12*(A30+1)),-1) & $-\mathrm{J} 31^{\circ} \mathrm{K} 31$ & $-G 31+L 31$ & $-1 / 2131 * 1000$ & $-\$ B S 3 / 1000 * N 31$ \\
\hline$-(1+5 B S 4)^{*}(12+(A 31+1))$ & $-\mathrm{H} 32 / \mathrm{B} 2$ & -PV(SBSA,((SESA*12)-12ฯ(A31+1)),-1) & $-\mathrm{J} 32 \cdot \mathrm{K} 32$ & $-\mathrm{G} 32+\mathrm{L} 32$ & $-1 / \mathrm{M} 32 \cdot 1000$ & $-\$ B S 3 / 1000 \bullet N 32$ \\
\hline$-(1+5 B S 4)^{*}(12 *(A 32+1))$ & $-\mathrm{H} 33 / \mathrm{L3}$ & -PV(SBSA,((SESA*12)-12*(A32+1)),-1) & $-533 \cdot \mathrm{K} 33$ & $-\mathrm{G} 33+\mathrm{L} 33$ & $-1 / \mathrm{M} 133 \cdot 1000$ & - SBS3/1000*N33 \\
\hline$=(1+\text { SBSA })^{*}(12 *(A 33+1))$ & $-\mathrm{H} 34 / 134$ & -PV(SBSA.((SESA*12)-12ฯ(A33+1)),-1) & $-\mathrm{J} 34^{*} \mathrm{~K} 34$ & $-G 34+L 34$ & $-1 / \mathrm{M} 334 \cdot 1000$ & $-5 B 53 / 1000^{\oplus} \mathrm{N} 34$ \\
\hline$-(1+\operatorname{SBSA})^{*}(12 *(A 34+1))$ & $-\mathrm{H} 35 / \mathrm{L} 35$ & -PV(SBSA,((SESA*12)-12*(A34+1)),-1) & $-J 35 \cdot \mathrm{K} 35$ & $-\mathrm{G} 35+\mathrm{L} 35$ & $-1 / \mathrm{M} 355^{*} 1000$ & -SBS3/1000^N35 \\
\hline$-(1+\text { SBSA })^{*}(12 *(A 35+1))$ & $-\mathrm{H} 36 / \mathrm{B} 6$ & -PV(SBSA,((SESA*12)-12*(A35+1)),-1) & $-536^{\circ} \mathrm{K} 36$ & $=G 36+L .36$ & $=1 / \mathrm{A} 136 * 1000$ & - $5 \mathrm{BBS3} / 1000^{\circ} \mathrm{N} 36$ \\
\hline$=(1+\operatorname{SBSA})^{*}(12 *(A 36+1))$ & $=\mathrm{H} 37 / \mathrm{L} 37$ & $=P V^{*}($ SBSA. $(($ SESA*12)-12*(A36+1)), -1$)$ & $-537 * \mathrm{~K} 37$ & $-G 37+L 37$ & $-1 / \mathrm{M} 37^{\bullet} 1000$ & -\$BS3/1000*N37 \\
\hline
\end{tabular}

